\title{
An Explorative Study of Virtues in Ethical Consumption from a Confucian Perspective in an Urban-Rural-Fringe in China
}

http://doi.org/10.21272/bel.4(4).105-122.2020

Dr Yan Huo, ORCID: https://orcid.org/0000-0003-3193-8264

$\mathrm{PhD}$, Postdoctoral Research Fellow, Center for Youth Moral Education, School of Public Policy and Management, Tsinghua University, Beijing, China

Kristján Kristjánsson, ORCID: https://orcid.org/0000-0002-8584-4178

$\mathrm{PhD}$, Professor, Jubilee Centre for Character and Virtues, School of Education, University of Birmingham, Birmingham, UK

\begin{abstract}
The concept of ethical consumption has garnered considerable attention in recent years. Yet, it remains somewhat 'mystical' in the existing Western literature. The present unique cross-cultural and crossdisciplinary study offers clarification on the conception of ethical consumption from three aspects: First, this paper reflects on the nature of the concept of ethical consumption and identifies its relatively large common core as an open-textured, 'naturalistic' concept; conceptualizing the ideal of ethical consumption in virtue ethical language. Second, this paper secures a firmer grounding for the concept of 'ethical consumption' within virtue ethics by linking it theoretically to a Confucian form of virtue ethics. We support this interpretation with empirical evidence, gleaned through focus-group discussions and individual interviews with consumers, undergoing fast-changing dynamics, from an urban-rural fringe from China: a culture already immersed in lay virtue ethical thinking, inspired by Confucius. Third, the paper brings the data back to theory by eliciting from the data a structural framework of the foci of the underlying virtues making up the virtue of ethical consumption, on our respondents' understanding, and reflecting upon how this new theoretical understanding may advance the academic discourse on ethical consumption and expand the understandings of ethical consumption from a cross-cultural perspective. We explore notions such as virtue patriotism and filial piety that contribute to the diversity of the conception of ethical consumption. We explain how those virtues play a role in Chinese understandings of ethical consumption, contributing to the global diversity of the concept. This study does not claim to represent the complete truth about Chinese consumers' views on ethical consumption, considering the geographic constraints and the small number of participants. However, it does offer some salient insights into Chinese consumers' understanding of ethical consumption, which is grounded in their daily practices and reflects their consumer motivations; hence, enriching the global business ethics discourse on ethical consumption.
\end{abstract}

Keywords: Virtues, The Concept of Ethical Consumption, Ethical Theories and Philosophies, Chinese Consumers, Confucian Virtue Ethics.

JEL Classification: D11, N3, P46.

\section{(i)}

This work is licensed under a Creative Commons Attribution 4.0 International License

Cite as: Huo, Y., Kristjánsson, K. (2020). An Explorative Study of Virtues in Ethical Consumption from a Confucian Perspective in an Urban-Rural-Fringe in China. Business Ethics and Leadership, 4(4), 105-122. http://doi.org/10.21272/bel.4(4).105-122.2020.

(C) The Authors, 2020. This article is published with open access at Sumy State University.

\section{Introduction}

The concept of ethical consumption has garnered considerable attention in recent years, both within the business ethics literature, more general business, and marketing literature and even within a larger sociopolitical discourse, often related to environmental and sustainability concerns. Yet the concept remains somewhat 'mystical' and anomalous in the existing Western ethical consumption literature (e.g., Devinney et al., 2010; Carrigan and Attalla, 2001; Joergens, 2006), a genre typically steeped in deontological or consequentialist assumptions (Barnett et al., 2005). Although some virtue ethically minded business ethicists have recently tried to take ownership of the concept (e.g., Garcia-Ruiz and Rodriguez-Lluesma, 2014), its 
accommodation there is hampered by the fact that Aristotle, back to whom most contemporary virtue ethics harks, had no similar virtue in his repertoire.

This article has a threefold aim. We first explore what sort of concept "ethical consumption" is and argue that its structure allows us to place it within the architectonic of a virtue: more specifically, a moral meta-virtue, i.e., a virtue that encompasses other virtues and augments them through mutual reinforcement. It prepares the ground for the reconceptualization of the ideal of ethical consumption in virtue ethical language. Second, the article aims to build on the concept of "ethical consumption" within virtue ethics by linking it theoretically to a Confucian version, which is more accommodating than Aristotle-inspired virtue ethics of virtues that incorporate different kinds of self-relational foci. We support this interpretation with empirical evidence, gleaned through focus group discussions and individual interviews with consumers undergoing fast-changing dynamics in an urban-rural fringe in China: a culture already immersed in lay virtue ethical thinking, inspired inter alia by Confucius. ${ }^{1}$ The third aim is to bring the data back to theory by eliciting a structural framework based on the foci of the underlying virtues making up the meta-virtue of ethical consumption, on our respondents' understanding, and reflecting upon how this new theoretical understanding may advance the academic discourse on ethical consumption and broaden its remit from a cross-philosophical perspective, such as by incorporating virtuous patriotism and filial piety. We explain how those virtues play a role in Chinese understandings of ethical consumption, contributing to the global diversity of the concept. Before addressing these aims, it will be instructive to provide an overview of some of the current state of play in this discursive field.

\section{Literature Review}

Conceptual Disarray or Healthy Pluralism? There is considerable evidence available on the negative impact of high consumption levels on various environmental, social and sustainability issues. Humphery (2011: 41) offers "ethical consumption" as a subversive concept, encapsulating Western anti-consumerism's rising tide. Its foil is the concept of (unfettered) "consumption" as an object of moral reprobation. The purpose of this subversive concept is then to reduce levels of aggregate consumption, in line with Singer's utilitarian advice (1997) that we should embrace "frugality". However, elsewhere ethical consumption is considered less as a discrete concept, with an exact core, than a set of problematizations and strategies. Ethical consumption is then not seen as a moral censure vehicle but simply as a medium for moral and political actions that can unleash methods such as consumer boycotts or fair-trade campaigns. No necessary implication is drawn here from the ideal of ethical consumption to the need for less consumption (Barnett et al., 2005); quite the reverse may hold, i.e., more consumption but not less being recommended, but to be attained more ethically, labeled as "positive buying" (Clouder and Harrison, 2005). Ethical consumption is, on this understanding, interpreted as a motivational concept, relating to "having political, religious, spiritual, environmental, social or other motivations for choosing one product over another" (Harrison et al., 2005: 2).

In line with this second understanding, according to which the ideal of ethical consumption can stimulate more consumption, many 'ethical products' can be seen in Western markets, from organic milk and free-range eggs to energy-saving light bulbs and bio-laundry detergents. According to a longitudinal study by the Co-operative Bank, sales of "ethical" goods grew more than threefold in 10 years, 1999-2010 (Co-operative Bank Report, 2011). A YouGov survey reported a 65\%-year growth from 2016 to 2017 in consumers stating that they had avoided buying a product or service harmful to the environment. Notably, in the West, the term 'ethical' in 'ethical consumption' is commonly understood from an environmental perspective rather than a traditional 'prosocial' one, although issues such as avoiding clothes produced in third-world sweatshops come up from time to time. In any case, from a marketing perspective, ethical consumption is more about choosing one product over another, for reasons that are somehow considered ethical, than suggesting less overall consumption.

However, there is mounting evidence that 'ethical consumption' in emerging markets, such as China, India and Turkey, has significantly different connotations from the Western ones. According to a cross-cultural examination (Devinney et al., 2010), consumers in emerging markets offer markedly different justification for their beliefs and behaviours regarding ethical consumption. These consumers tend to see general issues that many Westerners would frown upon, such as low wages in sweatshops, bad working conditions, nonenvironmentally friendly or animal-cruelty work processes and the purchase of counterfeit products, as "normal", "natural" or just 'the way the world works'. Devinney et al.'s (2010) study also suggests that consumers from emerging markets, such as China, attach meanings to ethical situations through the lens of

\footnotetext{
${ }^{1}$ We acknowledge that our empirical study, limited to one region in China, only illuminates parts of a putative Confucian conception of ethical consumption. Further studies, exploring alternative Asian Confucian cultures, such as Korea and Japan, would be needed for a fuller picture.
} 
their financial and political education and (a lack of) knowledge of ethical issues in their country. Their understanding of "ethical" is thus more localised and context-dependent than that of Western consumers. However, these are very general observations that call for further explorations, such as the present study, about what exactly 'localised' here refers to and how it encapsulates or fails to encapsulate ethical values - and then, in turn, how those values are grounded philosophically.

Deeper moral-cum-philosophical worries about universality versus relativity obtrude here, however. We know that consumers from different socio-cultural backgrounds often think, emote and, consequently, behave in ways different from one another (Wajda et al., 2007), for example, in societies with so-called independent versus interdependent self-concepts (Markus and Kitayama, 1991). These diverse factors work differently in different societies (Abdur and Hwee, 2002; Gao, 2013). Singer (2002, cited by Barnett et al., 2005: 12) suggests that there should be no restrictions on the scope of ethical concerns and the judgments of actions, in the sense that those should always be seen to depend on contextual factors. However, such an acknowledgement opens a Pandora's Box of ethical relativism, which would alienate most moral philosophers and business ethicists. Even for those who grant ethical relativity at the normative (overall) moral judgement level, some sort of commonality of understanding of what constitutes the "moral" or "ethical" seems to be presupposed. Otherwise, the debate is not about the same objects of inquiry and theorists will simply be partaking in different language games and speaking at cross purposes, without any potentially significant interactions. Enough has been said to indicate some conceptual disarray in the field of "ethical consumption" and almost as many conceptions of the concept as researchers are exploring it (Devinney et al., 2010). Conceptual purists, for example, within standard analytic moral philosophy, will look at such 'disarray' with a beady eye, while others, of a more postmodern orientation, might see it as a sign of healthy pluralism in a discourse that is rapidly evolving and inherently problematic in and by itself: a discourse where new meanings are continually being negotiated considering different power relations and cultural conditions.

We are not the first authors commenting on the difficulty of defining "ethical consumption" (e.g., Bray et al., 2010; Cherrier, 2005; Clavin and Lewis, 2005; Howard and Nelson, 2000). The difficulty is standardly summarised as being comprised of three significant aspects. First, as part of the broad consumption picture, ethical consumption contains various inter-related concerns and activities, and these contribute to its complicated nature (Lee, 2015). This point is thus about internal complexity. Second, the assessments and distinctions made in the name of ethical consumption can be subjective and complicated by local circumstances (Cherrier, 2005; Kent, 2005). This point is about context-dependence. Third, ethical consumption practices contain an extensive range of activities, and these various practices can sometimes be downright contradictory (Littler, 2010: 28). As a simple example of this, consider the "reduction of food miles" versus the "support of developing countries" (Real Think Tank, 2007). This point is about internal inconsistencies.

Fisher et al. (2009) indicate that the fundamental reason for defining a term is to facilitate communication. Hence, despite the above difficulties, more than a dozen definitions of ethical consumption have emerged in the literature (e.g., Shaw and Clarke, 1998; Crane and Matten, 2004; Harrison et al., 2005; Szmigin and Carrigan, 2006). To unpack two such definitions, O'Rourke (2006: 291) states that "ethical consumption is about taking the time to look beyond the clean, glossy packing to the background of what is presented, and making choices and purchases based on that knowledge". Smith (1990: 178) defines it as "an expression of the individuals' moral judgment in his or her purchase behaviour." Consumption, on the surface, may appear as simply being about buying items such as eggs and vegetables; yet there are deeply embedded, but often covert, ethical principles that can be found lurking behind those simple purchasing acts. As Burke et al. (1993) suggest, all purchasing behaviour is to some degree "ethical", as it involves moral judgement, made explicitly or implicitly.

No theorist seems to have so far asked the logically prior question of what sort of a concept "ethical consumption" is. Some concepts in social science and philosophy are family-resemblance or cluster concepts without a single common core. "Game" is the commonly mentioned example from Wittgenstein. Those concepts often function as umbrella concepts and are difficult to define because of no common essence. Nothing in the standard discourse on "ethical consumption" has persuaded us that we need to confine it to this amorphous category. Other concepts have a (small, vague) common core but are "essentially contestable" in the sense that theorists can disagree, with good arguments on each side, about which conception captures or illuminates the core best (Gallie, 1956). Such concepts are typically characterised by internal complexity, internal inconsistencies, and context-dependence: the very features that we identified in the case of "ethical consumption" above. However, concepts typically designated as "essentially contestable" (such as "freedom" and "power") tend to be subject to intense political debates in areas where the level of consensus is minimal. 
Although "ethical consumption" is a contested concept, it seems an exaggeration to designate it as being essentially so. It is a concept with a large common core - any theorist will intuitively know broadly what sort of conduct is being referred to - and debates seem to focus on the margins of the concept and its applications rather than the fundamental essence motivating it. Therefore, we consider the label of an "open-textured, naturalistic" concept to capture its nature best (Kristjánsson, 1996). Such notions have a relatively large common core, although debates may rage about many borderline cases. Examples of open-textured concepts are various virtue ethical ones, such as "virtue" or "flourishing". These concepts are also typically threshold concepts. To fall under a threshold concept $\mathrm{C}$, an item $\mathrm{X}$ does not need to be fully $\mathrm{C}$ but just satisfactorily so (Kristjánsson, 2020). The question of whether a given conduct counts as ethical consumption is then not the question if it satisfies all the concept's necessary and sufficient conditions but whether it makes the grade in the sense of fulfilling some minimal requirements concerning the essence of the concept.

Ethical Theoretical Provenance. To get a better hold on why "ethical consumption" is an open-textured and in some ways a contested concept, rather than a closed one with clear-cut necessary and sufficient conditions for inclusion, it is instructive to explore the ways in which different theorists have claimed different theoretical provenance for it. In other words, there are significant debates about its accommodation within the three standardly competing ethical theoretical paradigms. A deontological, Kantian or rule-based approach used to be the dominant approach within business ethics and it still prevails in substantial parts of standard business ethics education, although it tends not to be adhered to by budding business-education students and to lose traction among experienced businesspeople in the field (Huo and Kristjánsson, 2018). Deontologists invoke universalizable maxims about people's responsibilities towards others, such as to other people, animals, the environment, or future generations. For example, the deontological logic to refuse to purchase child-labour products, as part of ethical consumption, is based on the principle that it violates a fundamental moral rule against the exploitation of children. In addition, several deontologists have extended the traditional boundary of ethical concerns to nonhumans, proposed as "animal rights" or "rights of the environment" (Regan, 2004; Reynolds, 2019).

A consequentialist approach critiques the deontological one for being too inflexible and formalistic and not take account of general utility maximisation in the world. Grounded in concerns for making the world an overall happier place, consequentialists promote several business practices such as Fair Trade, organic produce, green products, non-genetically modified crops, labour standards and animal welfare - and oppose or boycott others, such as No-Sweat or anti-sweatshop and unethical brands/products. Ethical consumption, on this approach, covers almost every aspect of life, illustrated by research undertaken in different sectors such as fashion, clothing, eating, drinking, banking and tourism. Virtue ethics is less concerned with our reasongrounded duties towards other, or the greatest happiness/utility of the greatest number, emphasising more the cultivation of personal excellences qua virtues (including virtuous emotions) and societal flourishing (Maclntyre, 1981; Solomon, 2004; Sison et al., 2017; Barnett et al. 2005; Garcia-Ruiz and Rodriguez-Lluesma, 2014; Kristjánsson, 2020). Garcia-Ruiz and Rodriguez-Lluesma (2014) point out that moderate consumption can be a context for developing positive character traits leading to human flourishing. Character virtues documented by Peterson and Seligman (2004), such as courage, humanity, justice, temperance and perspective, may all feature to a greater or smaller extent within a paradigm of virtue ethical consumption. In general, a virtue ethical approach moves away from focusing on questions such as 'what are the consumption outcomes?' or 'what is the right rule for consumption?' to "what sort of person, qua consumer, ought I strive to be?". Until recently, virtue ethics in business ethics was almost exclusively explored under a Western (Aristotelian or MacIntyrean) lens. That is now changing, however, with increased focus on Eastern, especially Confucian, perspectives (Alzola, Hennig, and Romar, 2020).

Barnett et al. (2005: 13-15), in their discussion of philosophy and ethical consumption, apply well-known objections to deontology and consequentialism to the area in question. First, they both present ethical conduct models as being too stringent in the demands that they make on ordinary people's capabilities, for instance, through rigorous requirements of impartiality even when the interests of significant others are at stake. Second, these models are overly inflexible, leaving little room for ethical decision-making complexities and ambivalences. Third, both models ignore the important symbolic roles of consumption in the ordinary lives of people, failing to acknowledge that material goods serve more functions than merely providing basic needs; they also serve to facilitate interpersonal interactions, thus helping to form a sense of identity and self-worth: the socially and emotionally driven aspects of consumption for ordinary consumers. Garcia-Ruiz and Rodriguez-Lluesma, (2014: 525-526), through their discussion of a virtue ethics approach to consumption practices, highlight inter alia three advantages of virtue ethics for analysing ethical consumption: a) it helps to explore the developmental dynamics of consumers (e.g. consumer identity and consumer culture theory) which 
deontological and consequentialist approaches fail to do; b) it emphasises consumers' developmental dynamics with the integration of everyday consumption in practices of everyday life; c) it is a practical approach that is apt for inducing people to consume moderately, thereby fostering human and environmental flourishing through the virtue of temperance. Similarly, Barnett et al. (2005, 16-17) comment on the usefulness of a virtue ethics approaches to ethical consumption, in that by recognizing that all consumer behaviour, however ordinary and routine, is likely to be shaped by the diverse values of caring for other people and concern for fairness, it pays attention to the mundane habits and practices through which virtues are cultivated. Therefore, it is well placed to discuss which everyday habits and practices may help lead consumers towards ethical consumption. Furthermore, virtue ethics is particularly useful in researching ethical consumption because of consumers' prime internal motivation of "personal integrity" (Kozinets and Handelamn, 1998; Shaw and Shiu, 2003). Most generally speaking, because of its ethical naturalism, according to which all ethical theorising is answerable to empirical evidence on what makes ordinary people tick, virtue ethics listens to the voices of those that Aristotle called "the many", not only "the wise" (Kristjánsson, 2020). Finally, virtues are known to have intrinsic motivational force for ordinary people, which may be lacking in the case of more abstract principles of universalisable reason or general beneficence.

From Aristotelian Virtue Ethics to Confucius. While we happen to be in broad, if uneasy, agree with the arguments favoring a virtue ethical approach to ethical consumption, we consider it to face two serious obstacles. The first one is practical and the second theoretical. The practical problem is that despite a rapidly growing mountain of literature on virtue ethics within business ethics, in general (e.g., Alzola, 2015), and the ethical consumption literature, most of this work is fairly abstract and theoretical. For instance, while certain individual virtues have been highlighted in previous studies, such as frugality (Singer, 1997), integrity (Kozinets and Handelamn, 1998) and thrift (Chesterley, 2016), the relevant literature has yielded scant suggestions about how to reconceptualise the ideal of ethical consumption in virtue ethical language. For instance, by systematically listing the virtues that it would encapsulate and how those could be cultivated, say, through character education or business-ethics education. As a first step, it might be easier to do this within a culture that is already steeped in virtue ethical language through its lay moral outlook. Hence, our decision to focus on China, with its rich Confucian virtue ethical tradition, in the empirical part of the paper.

The second problem is that while the ideal of ethical consumption is becoming increasingly aligned with, and even absorbed into, a larger agenda of sustainability, and hence being brought into closer collaboration with environmental ethics, contemporary virtue ethics in the West, mostly derived from Aristotle, has a tough time keeping up with this development or even making sense of it. The simple reason is that Aristotle was a "people person", fairly hostile to respect for non-human or abstract moral ideals. Once bitten, twice shy concerning the idealism of his mentor Plato, Aristotle thus only categorised moral virtues that relate to oneself (like proper pride), other people (like generosity) or external events, often brought about through human agency (courage in war, for example). There is no space in Aristotle for awe at the wonders of the universe or respect for beauty or nature qua moral virtues. Neo-Aristotelian virtue ethicists have tried to ameliorate those shortcomings by adding new 'Aristotelian' moral virtues to Aristotle's original arsenal, for instance, the virtue of harmony with nature (Jordan and Kristjánsson, 2017). However, those attempts appear contrived, for although the form of the proposed virtues can be made compatible with Aristotle's standard architectonic, the substance is essentially un-Aristotelian. To cut a long story short, Aristotle had no special interest in sustainability or ethical consumption and attempted to ascribe those modern concerns to him are rather far-fetched. Moreover, although Aristotle can be "updated" or other Western virtue ethicists used as reference points, for example, MacIntyre (cf. Garcia-Ruiz and Rodriguez-Lluesma, 2014), the whole Western tradition tends to understand environmental virtues in an anthropocentric way (i.e., through the logic of sustainability) rather than in a deepecological way (i.e., through reference to harmony with nature). ${ }^{2}$

Confucius can come to our rescue on this theoretical front also, however. Although there are striking similarities between Aristotle's and Confucius's brands of virtue ethics (as compared, e.g., in Yu, 2007, and Sim, 2007), Confucius does carry certain advantages over Aristotle. For one thing, Confucius was not shy of positing moral virtues directed towards abstract ideas or metaphysical entities, such as Heaven (Tiän) - an impersonal force ordering the universe, responsible for fate - and the Way (Dào) (Kristjánsson, 2020: chap. 7), and he had a discrete non-anthropocentric virtue of harmony with nature. To be sure, Confucian teachings,

\footnotetext{
${ }^{2}$ While we want to avoid the objection that we are caricaturing Western virtue theory as solely Aristotelian, and then ascribing deficiencies in environmental conceptions to Western virtue theory based simply on Aristotle's putative lack of moral interest in the natural world, we remain unconvinced that, say, MacIntyre's version of virtue ethics escapes this criticism. Contra Chu and Moore (2019), we see MacIntyre's (1981) quasiHegelian view of virtues embedded in social practices as being incompatible with the strong cosmopolitan streak of Confucian virtue, and although MacIntyre's later (1991) reconstruction of Aristotelian naturalism opens the door to cosmopolitanism, it is still far removed from the essentially nonanthropocentric Confucian metaphysics.
} 
represented by the Analects, do not teach consumers how to shop or what to purchase directly. However, they give instructions on becoming a good human person, known as jun-zi (君子), and live a virtuous life. Jun-zi is a moral exemplar (like Aristotle's phronimos) who cultivates his virtues in everyday life through doing all kinds of commendable activities. Therefore, indirectly, the Analects offer moral advice about consumers' consumption practices, and it is possible to articulate specific virtues that an ideal ethical consumer would exercise in a Confucian context.

Confucian Virtues. The principal virtue in Confucian teachings is ren-yi (仁义), benevolence ${ }^{3}$ and righteousness, which can be viewed as the mother of all Confucian virtues. The virtue xiao-ti (孝悌), filial piety, is considered as the root for ren-yi; therefore, practising xiao-ti within the family is fundamental to achieving a virtuous life. This virtue implies that a filial child must take on obligations towards his/her parents, such as carrying the responsibility of taking care of the parents physically, mentally, socially and spiritually. The complete view of filial piety is expressed in the Confucian Analects, and the Classic of Filial Piety (xiaojing, 孝经) advises on filial piety; that is, how to behave towards a senior. Confucius set an example of how one should live virtuously by praising his disciple Hui Yan. The Master said: "What an extraordinary man was Hui! Living in a shabby neighbourhood on a bowlful of millet and a ladleful of water, most people could not have endured such misery, but Hui did not let it take anything away from his joy. What an extraordinary man was Hui" (Analects, 2014: 85). The Master's words show that Confucius encourages living thriftily and humbly. According to the Chinese Confucius researcher Kong (2007), Confucius' teaching has had an important impact on Chinese consumption values: the virtue of thrift is considered as the prime virtue in consumption. Traditional Chinese cultural values do not offer much direct input on animal welfare. Indeed, in this respect, Confucian moral philosophy is as human-centered as Aristotle's. However, Confucian views on the environment/nature are heavily based on cosmic principles and state that Heaven instructs human conduct and establishes moral principles. The Great Learning and The Doctrine of Mean have important implications for human-nature relationships (Ouyang, 2015). Those carry a practical message about how humans should use resources in nature to sustain their livelihood. Confucianism emphasises that humans and nature constitute a "continuum" and form "one body", since humans and a myriad of things in the universe share the common attribute of "benevolence" (Huang, 2005). Therefore, the virtue of harmony can be negotiated between humans and nature. For instance, the Confucian view acknowledges that it is morally acceptable to use natural resources and animals as food to support human life, but in a harmonious way - which goes beyond what would probably be articulated in the West as a 'sustainable way'. Confucius can, therefore, without falling prey to anachronistic thinking, be considered a true environmentalist.

\section{Research Methods}

Under the guidance of phenomenology (Langdridge, 2007) and narrative inquiry (Webster and Mertova, 2007), the study reported here aimed to explore Chinese consumers' perceptions of ethical consumption and what it means to them, with a focus on their lived experiences. Focus-group discussions and interviews were conducted to obtain both individual and collective views. The fieldwork was conducted in Changping district, a typical urban-rural-fringe area in Beijing, mirroring China's fast urbanization process. Unlike previous studies with "committed ethical consumers" (Bray et al., 2010), this study recruited ordinary consumers from various backgrounds to provide an authentic Chinese perspective. A total of 35 participants (see Tables 1 and 2), comprising four focus groups (19 participants) and 16 interview participants, were selected through convenience sampling (ages from 20 to 65) to obtain the right mix. The participants were everyday consumers in the Changping district. The first author used her social network to find "gatekeepers" willing to help look for suitable participants. We did not apply a rigid rule in selecting participants but applied a relatively flexible approach. Similar gatekeepers (e.g., from the same office, same company, same neighbourhood) were avoided. In this way, it was possible to make sure the participants constituted a heterogeneous mix from an urban-ruralfringe context. We realize that our convenience-sampling method and the reliance on interviewees from a single district in China invite representativeness problems. Originally, we planned this as a tentative case study, or pilot study, only - to be extended to a larger sample later. However, the richness of the data gathered, and their salient theoretical and ethical implications persuaded us to make do with the current data set and focus more on ethical, theoretical considerations in the present research project, as will become apparent in subsequent sections of this article.

\footnotetext{
${ }^{3}$ We acknowledge that Renxue, The Doctrine of Ren, can be translated as humanness or humanistic spirit, derived from its global implications or overall meanings; the common translation of the concept of ren is benevolence, based on a literal translation (e.g. Tu, 2014).
} 
Table 1. Focus-Group Participants

\begin{tabular}{|c|c|c|c|}
\hline Group Name & Participants number & Participants age & Major social roles \\
\hline Focus group 1 & Four & $26-30$ & Earlier career \\
\hline Focus group 2 & Five & $45-65$ & Factory workers \\
\hline Focus group 3 & Five & $31-44$ & Young parents \\
\hline Focus group 4 & Five & $20-25$ & University postgraduate students \\
\hline
\end{tabular}

Source: Compiled by the authors

Table 2. Interviewees

\begin{tabular}{|c|c|c|}
\hline Participant & Gender and age & Participant information (occupation and education) \\
\hline $\mathbf{1}$ & Male, 64 & Manager in a local factory, Adult Professional College Degree \\
\hline $\mathbf{2}$ & Male, 42 & Director in the government sector, Adult Professional College Degree \\
\hline $\mathbf{3}$ & Female, 43 & Shopping mall consultant, Adult Professional College Degree \\
\hline $\mathbf{4}$ & Male, 34 & Fried chicken shop owner, High school \\
\hline $\mathbf{5}$ & Male, 31 & IT worker, College Diploma \\
\hline $\mathbf{6}$ & Male, 36 & Civil servant, Diploma \\
\hline $\mathbf{7}$ & Male, 33 & University lecturer, Master's Degree (Japan) \\
\hline $\mathbf{8}$ & Female, 40 & Home designer, College Diploma \\
\hline $\mathbf{9}$ & Male, 32 & Nurse, Secondary School with extended training \\
\hline $\mathbf{1 0}$ & Male, 27 & Supermarket assistant, College Diploma \\
\hline $\mathbf{1 1}$ & Male, 32 & Buyer in a local factory, College Diploma \\
\hline $\mathbf{1 2}$ & Female, 26 & Eccountant in a hospital, Master's Degree (Hong Kong, China) \\
\hline $\mathbf{1 3}$ & Female, 25 & Employed by family business, Primary School \\
\hline $\mathbf{1 4}$ & Female, 26 & Auditor in a pharmaceutical company, Bachelor's Degree \\
\hline $\mathbf{1 5}$ & Male, 38 & General manager of a private environmental planning company, Master's Degree \\
\hline $\mathbf{1 6}$ & Male, 40 & \\
\hline
\end{tabular}

Source: Compiled by the authors

A phenomenological approach assumes that we experience pre-reflectively, without resorting to categorisation or conceptualisation, and this often incorporates what is taken for granted and those things that are commonsense or even seemingly trivial aspects in our lives (Husserl, 1970). Based on such understanding of the "lifeworld", both the focus group discussions and interviews were conducted with prepared questions (i.e., were semi-structured): on the one hand, using the questions as prompt, on the other hand, encouraging participants to share their ordinary experiences and life stories which might seem trivial yet meaningful. The prepared questions were developed based on the literature review, such as prevailing ethical concerns about the environment, animal and human rights and typical products (e.g., soaps, Nike trainers, fruits and vegetables, eggs, etc.). For each of the concerns, there were three levels of questions. Taking environmental problems as an example, the three levels of questions were: general questions, such as "Can you remember what you purchased in your last shopping?"; then, based on their answers, key questions were asked about the products they purchased, such as "What are your concerns with purchasing the products?" Finally, specific questions were asked based on the relevant products that could be related to established ethical issues, such as "What's your opinion on organic produce?" The aim was to understand the respondents' "consumption worlds" and establish their purchase behaviours, motivated by their underlying concerns and deeper values.

Ethical considerations were of prime importance throughout the research (Clandinin and Huber, 2007: 15). All participants were given consent forms and the research work was conducted under the University of Gloucestershire ethical guidelines. A voice recorder was used to record all the conversations and later transcribed into text, initially in Chinese, then partially translated into English afterwards. Participants' real names were hidden and coded names, such as Interviewee 1 for interviews and Participant 1, G1, for focusgroup participants, were adopted. This study relied on three key qualitative research criteria: trustworthiness (Shenton, 2004), authenticity (Percy, 2006) and rigour (Silverman, 1997). Thematic data analysis was adopted both manually and with the aid of the NVivo qualitative data analysis tool. The data-analysis process followed a procedure developed by Braun and Clark (2006). The initial themes were superficially elicited at first, solely based on the three main ethical concerns (namely, environment, animal, human/society), to collect similarities in participants' responses towards various ethical purchasing decisions. For example, consumers' comments regarding organic produce were grouped together initially under the first-order theme "When Chinese consumers meet the Western concept of ethical consumption" and then subjected to deeper second-order analysis under the theme "What does ethical consumption mean to Chinese consumers?" With respect to issues that seemed to depart from Western understandings, we dug into why those understandings did not resonate with them, based on their cares and concerns - identifying key words, patterns and themes, repeated by different interviewees and group participants, until a saturation point was reached. By trying to chart the two- 
way traffic between their actual (ethical or unethical) concerns in their shopping events, on the one hand, and their underlying values, on the other, we tried to figure out why they chose to tell certain emotion-laden stories and what those meant to them. From analysing the "trivial" and often apparently taken-for-granted stories, we identified the central themes of those stories, often related to their family members, revealing key virtues (e.g., filial piety) rooted in their (e.g., Confucian) values and speaking through them in their everyday consumption behaviours. These key virtues were then pulled out and discussed between the two authors to ensure trustworthiness and rigour. Five themes are presented in the Findings section, supported with texts extracted from the Chinese consumers' shopping experiences and life stories.

\section{Findings}

Family is the Centrality. The first important ethical dimension among Chinese consumers is centred around a social unit: their family. Participants naturally and spontaneously mentioned family members in relation to their consumption practices. Their consumption stories and experiences were surrounded by "my mum", "my dad", "my child", "my son", "my daughter", "my husband" and "my wife": their key family members. It demonstrates that for these individual consumers, the consumption activity is not just about a personal choice or concerns, it closely relates to wider concerns for other family members, known as guan-xi (关系) or kingroup. Participants expressed concern for their children and for aging parents. For example, a father (Interviewee 7) purchased New Zealand kiwi fruit, which is seven times more expensive than an ordinary kiwi fruit, just because of his son's preference. A mother, who spent over 2,000 RMB (half of her month's income) on importing baby formula for a single purchase, said: "I do not mind how much money I spend on my child..." (Participant 2, G2).

Interviewee 1 recounted this story: “About fifty year ago...a Chinese New Year's Eve, our family were all gathered together. My grandma and my mum together made dumplings with that precious pork. When the dumplings were ready, we were all sitting around the table, chewing the dumplings slowly and enjoying this once-a-year treat...my second brother finished his dinner before anyone else and then he said he was full...we were all surprised as he had had much less than he normally had... anyway.... After we all finished the meal and mum was about to clean the dishes... my second brother came and asked: are there any leftovers? Mum started: why did not you eat properly earlier.... My little brother had tears in his eyes and said: I just wanted to make sure everyone was satisfied first..." This consideration is the glue that cements the place of ren-yi by putting the family above oneself. From the Chinese consumers' stories, it can be sensed that ethical consumption is not simply a reaction to an external, distant ethical concern; there is a family bond, stronger and more enduring, underneath. In sum, an ethical consumption decision is here seen as a decision that benefits a family member interdependently, rather than the consumer independently.

Necessity, Modesty and Thrift. The second important ethical dimension among the Chinese consumers is constituted by ethical concerns that are embodied within themselves. Instead of foregrounding external values, they highlight internal concerns, states of character, and the need for cultivating virtues such as thrift and modesty, including the fundamental principle for ethical consumption which is focusing on 'necessity'. This can be illustrated by the following quotations from participants:

"My understanding of ethical consumption...is living thriftily..." (Interviewee 3).

"Yes, that may be an ethical product, very nice, but do I really need it? I am not buying it because it is an ethical product; I only buy it because it is a necessary product. So, when I consume, firstly, I think if it is necessary..." (Interviewee 8).

Rather than emphasising which product is more ethical, or their 'ethical' choices, Chinese consumers pointed out the fundamental issues of consumption: the necessity to consume. Participants' comments reflect that the nature of being 'ethical' can be very different for different consumers. It is purchasing for necessity, not simply something that has an ethical label or logo. This contrasts with the current mainstream thinking about Western ethical consumption ${ }^{4}$ and ethical marketing, which encourages subjectively motivated ethical consumption behaviour as such (irrespective of the objective need for the product) and guides consumers to purchase certain ethical products (see e.g. The Ethical Consumer magazine). Unlike committed Western ethical consumers, who (because of extensive media exposure) are likely to be equipped with knowledge of ethical issues, comparing alternative products to figure out what would be the most ethical choices in each product range, an

\footnotetext{
${ }^{4}$ We unapologetically make comparisons to Western understandings of 'ethical consumption' in this section. What we are interested in are the conversations between two perspectives on the same open-textured concept of ethical consumption. We believe that the dialogue between Confucian consumers and Western views can generate novel dynamics across schools of thoughts and provoke new thinking and understandings.
} 
ideal Chinese ethical consumer may or may not be familiar with these ethical issues, but is simply directed by "buying necessities". Buying what is necessary shows respect for the traditional Chinese cultural value of "thrift". By suggesting that buying what is necessary is ethical, participants are suggesting that buying things that are not necessary is unethical. Interviewee 9 provided an example to illustrate what he thought "ethical consumption' is: "Ethical consumption to me is spending based on my income; consuming within my ability." He then utilised the case of his car purchase to demonstrate what he thinks is reasonable and ethical. ${ }^{5}$ The participant suggested that it is important to spend based on one's income. Such a view also reflects Confucius' view on consumption where "living within your means and being moderate in consumption" is considered a Confucian virtue (Kong, 2009). ${ }^{6}$ Moderate consumption can also reflect admiration of 'moderation' in traditional Chinese culture. Confucian teachings suggest that an ideal state is balanced and harmonious, by neither doing nor having too little nor too much. This demonstrates the other aspect of an ideal Chinese ethical consumer who lives within his means: living moderately.

Trustworthiness. The third important ethical dimension in Chinese consumers' consumption is their concern in relation to trusting businesses. Chinese consumers struggle with 'trustworthiness' in their consumption life: to trust business claims, such as the "free-range", "organic" labels. To give an example, Interviewee 5 witnessed his own uncle placing ordinary eggs in boxes with free-range labels on it to make profit. This naturally generated scepticism towards this type of ethical concern and labelling. This type of view is common among Chinese consumers, i.e., they value the virtue of trustworthiness but often see it being flouted. Furthermore, this lack of trust was not confined to ethical labels but extended to more extreme cases. How can consumers still trust a business when their health and lives are threatened by consuming certain products? Food safety is not a primary consideration in Western writings about ethical consumption; however, it predominates in Chinese consumers, crystallised in the San-Lu incident where a well-respected company with over half-acentury's history sold poisoned infant formula in 2008. “...they do not have an ethical boundary. Say, poisoned milk powder, how can they make this, poisoned infant formula for babies? For they only care about profit. They did not think about the outcome that is harmful for (killing six babied and 3000,000 were affected) lots of baby's lives..." (Interviewee 8).

Interviewee 8, a young mother, expressed her strong feelings in the above extract, where issues around the "infant" were given special attention, as one of the most striking ethical consumption issues for Chinese consumers in recent times. The rationale for the prioritisation of the "infant" and its use in the demonstration of a moral verdict can be traced back to Confucian wisdom, witness the famous story by Mencius of how everyone, good or bad, will be upset by seeing a child about to fall into a well. Given this cultural background, it helps to explain the significance of the infant formula and its damaging effects on Chinese consumers, and why they categorise this as a fundamental ethical consumption issue. "Who can we trust?", more than one participant asked. From the participant voices, we can also hear the call for responsible companies to protect "the vulnerable". Such vulnerability can be viewed as symbolising the Chinese consumer. Living in the shadow of a series of food safety scandals, they need companies to be responsible and to produce safe products. When companies fail to do so, consumers' confidence is ruined and the trust between consumers and the companies is broken. The story of the infant formula sends out a strong message, a call for the re-establishment of trust. Trust, known as cheng-xin in Chinese, is regarded as the one of the most fundamental virtues in Confucian moral teachings. Thousands of years has gone by; yet this core of the Chinese virtue remains as valuable as ever, especially in the currently problematic Chinese market. These interviews revealed that, even more so than in the West, the Chinese concept of ethical consumption is intimately linked to the idea of "responsible business". The latter needs to be trustworthy for the consumer to be able to exercise the virtue of trust. Without such virtuous foundations, there will be no ethical consumption.

A Sense of Patriotism. Patriotism is not an Aristotelian virtue, and it has fallen into disrepute in much of liberal Western political theory. However, the interviews revealed a different story in China. The fourth important ethical dimension among Chinese consumers was demonstrated through their concerns in relation to their nation. ${ }^{7}$ Not all the Chinese consumers thought purchasing counterfeit products is "unethical"; indeed, many of them considered it normal, consistent with findings in the literature. Moreover, some participants suggested

\footnotetext{
${ }^{5}$ Notice here that domestic consumption in China, as a proportion of national GDP, remains low in comparison with countries such as USA, UK and even Japan (Sigurðsson, 2014).

${ }^{6}$ Therefore, Confucians are rightly considered as frugalists, although they also reject miserliness as the unwanted excess of frugality. Attempts to dress Confucianism up as sympathetic to high-consumption capitalism, as suggested for example by the Singaporean government in the 1980s and 1990s, are thus essentially misguided (see Sigurðsson, 2014).

${ }^{7}$ We realise that some instances of 'patriotism' illustrated below may be not constitute a virtue to some. We consider it a putative virtue, however, at least in the overarching sense of "vitality" (McGrath and Walker, 2016): a sense of "emotional engagement with the world", here emotional engagement qua love of the motherland.
} 
that it is better to buy [Chinese] counterfeit products than to support Western companies such as Nike or Apple. A sense of this 'nationalist' overtone can be seen in the conversation below: "Real Nike shoes or fake Nike shoes cannot be distinguished. They are often made in the same factory..." (Participant 1, G4). "Foreign brands such as Nike, I think we should try to avoid them because most of the profits are taken by the other countries. Domestic brands, we should support more...?" (Participant 3, G4). "My old mobile was an iPhone, but I'm very pleased and proud of my new Huaiwei..." (Participant 16).

Ethical concerns here shifted from the "individual level" to a "national level". Participants suggested that it is essential to support domestic brands and expressed their concerns that foreign brands or companies are the biggest winners from Chinese consumers' purchase choices. A sense of patriotic feeling was aroused. Some participants expressed this even more directly, for instance: "I support national produce...thinking of Diaoyu Islands [a territory under dispute with Japan], I am anti-made-in-Japan" (Participant 2, G2). It is not something new to be "anti-certain countries" produce. For example, "anti made-in-China" was one of the protest slogans in the Western world in the name of the Free-Tibet movement. Other more positive campaigns have been supported for "Made in the USA" and "Germany buys German made". In this sense, Chinese consumers reactions are just like those of consumers from other parts of the world. It reflects that consumer behaviour, especially when boycotting a product, often represents a certain political stance. It further highlights the complicated nature of consumption behaviour; it is naive to study it in a vacuum without acknowledging the complexity (e.g., political, cultural, and historical) inherent in the consumption environment. The above example demonstrates that political stance is one of the contributors to such complexity, in Chinese consumers' sense-making of ethical consumption. From this perspective, having a sense of patriotism is an essential component of ethical consumption for Chinese consumers.

Harmony is the Ideal State of Being. The fifth important ethical dimension for Chinese consumers is to respect nature: to achieve a sense of balance and harmony (a Confucian virtue). Since the literature search already established that Western ethical concerns are often being perceived as very distant in emerging markets, including China, it is not a surprise that a participant responded: "it is better to test on animals, as it should be safer for consumers" (Participant 2, G3). Participants even suggested that it is not appropriate to care for animals' welfare when there are people still suffering and their living conditions are not better than those of caged chickens (Interviewee 1). This section reveals the relationship between Chinese consumers' conceptions in relation to nature, using animals as an example. From the stories below, it explains some of the practical reasons for the lack of fit to Western animal welfare concerns; in addition, it offers an account of the Chinese consumers' perceived sense of 'animal welfare', following the "natural law': "I do not look for free-range; I would be happy if the chicken is not a "fast growing chicken." (Interviewee 7). "Fast growing chicken does not taste good. It doesn't have that succulent real chicken flavour... Fast growing chicken should be prohibited, very unnatural and it is against the natural law." (Participant 3, G 4).

The notion of "fast growing chicken" has drawn considerate attention among Chinese consumers. "Fast growing chicken" can be also associated with one of the food safety problems in China. This kind of chicken refers to certain husbandry methods that poultry farms use where lights are always used to encourage birds to eat non-stop and grow faster. Such methods also use antibiotics to accelerate the speed at which a chicken grows, which although beneficial to the business, can be inhumane to the chicken and produce toxic meat that is harmful for consumer health. The participant not only mentioned that the taste of fast-growing chicken is not good; but also stated that it is something "unnatural" and "against natural law". Although the participants expressed their concerns represented by fast growing chickens, their concerns were motivated by their selfinterest such as with the taste and health concerns. No direct concerns were given to the chickens' welfare. However, one participant mentioned "nature" and "natural law", viewing fast growing chicken as something unnatural. Doing things in a natural way shows respect to nature, including animals. The Chinese consumers' point, regarding principles in relation to animals, is to respect nature. When we do so, things will fall into the right place. Things like fast growing chicken would then not exist. Chinese consumers' perception in relation to animals is, however, not solely a perception of animals, but a perception of human beings in-the-world, using animals as a resource, maintaining harmony with nature. Hence, lack of empathy with animals - which some Westerners might interpret as going against harmony with nature - is understood by Chinese consumers as being in accordance with a natural, harmony-preserving law of nature.

\section{Discussion}

The empirical study findings support the literature in that consumers from emerging markets tend to have a very different justification for their consumption beliefs and behaviour (Devinney et al., 2010), by providing consumers' responses and consumptions stories; also highlighting the general importance of culture in 
understanding consumers (Gao, 2013). Chinese traditional virtues are still deeply embedded in Chinese consumers, speaking through them, and influencing their construction of the meaning of ethical consumption. The empirical study further investigated the role of traditional Chinese cultural virtues in consumers' behaviour, represented by Confucianism, highlighting how specific virtues such as harmony, thrift, and trustworthiness impact on Chinese consumers' construction of the meaning of ethical consumption. ${ }^{8}$ In addition, it pointed out the importance of relationships (guan-xi) in the sense-making of Chinese ethical consumption, as virtues do not operate alone but "hunt in packs". They tend to be more meaningful when located in specific relationships such as the reflexive self-relationship, family relationship, consumer-business relationship, consumer-country relationship, and consumer-nature relationship. Ethical consumption, therefore, cannot be understood as simply "choosing one product over another" in the Chinese context. More generally speaking, ethical consumption should be approached via its underpinning moral philosophies, based on the relevant consumer cohorts and their national contexts.

The interpretation of Chinese consumers' accounts of the meanings of ethical consumption was a constant looking-back-and-forth process between the literature review and the data sets. Chinese consumers' understandings of ethical consumption were not homogenously unified. Their interpretations of ethical consumption were largely based on their lived life experiences; thus, the construction of the meanings of the concept turned out to be impacted by various elements such as traditional cultural, social and political contexts; historical as well as contemporary dynamics in China. Among all these influences, it became evident that the Confucian moral vision, represented by a set of virtues, is still deeply rooted in Chinese consumers. This showed that the Chinese ethical consumption is not the rights-based one that the Western ethical consumption presented, at least until recently (prior to the resurgence of virtue ethics); it represents a distinctive Confucian virtue-based moral vision. This explains why some of the Western ethical concerns are perceived as being alien to Chinese consumers, such as animal welfare concerns, or in sharp contrast to Western ethical concerns, such as their attitude towards counterfeit products. In addition, virtues do not work alone in Chinese consumers' understandings of ethical consumption. Virtues are placed in a specific context with corresponding key relationships. For example, Chinese consumers emphasise the central consideration for their family members in the case of purchasing baby formula and New Zealand kiwi fruit, and they highlight the virtue of trustworthiness in relation to free-range eggs and organic labels.

Western rights-based moral ideas, such as animal rights, were not present in the Chinese consumers' understandings of ethical consumption. Instead, five key virtues in correspondence to five key relationships became evident - self and self, self and family, self and business, self and nation, self and nature - where each of the relationship highlights also at least one key virtue, illustrated in Figure 1. The self-and-family relationship is placed as priority over oneself, exemplified by the virtue of love (rooted in filial piety) for family members. In the reflexive self-relationship, purchasing should be based on necessity; it implies self-cultivation, self-control, and self-regulation that one exhibits a modest and thrifty lifestyle. In the self-and-business relationship, the virtue of trust is emphasised by Chinese consumers; it also represents Chinese consumers' demands for regulation of Chinese ethical consumption. In the self-and-nation relationship, a sense of patriotism was aroused that is consistent with Chinese political and social conditions. The self-and-nature relationship implies that a harmonious state follows the natural law, showing respect to nature.

\footnotetext{
${ }^{8}$ We may seem to be taking an illegitimate logical step here in interpreting the views of our interviewees as representing a Confucian tradition. This might be considered a selected or favoured interpretation, neglecting the diversity of China's own religious history. For example, thrift in the sense of moderation regarding material desires is also expressed in Daoism, as well as one's relation with nature, which is even more explicitly expressed there as the idea of a cosmic, all-encompassing harmony. It is well known that religious and ethical paradigms are not as well differentiated in the Chinese context as they are in the West. However, given that paradigms such as Daoism and Mohism express a much stronger aversion to consumption and material wealth than does Confucianism, their followers would be expected to express a more radical sense of frugalism than our interviewees did (cf. Sigurðsson, 2014). The moderate frugalism expressed by our interviewees - friendly to consumption but only within reasonable limits - seems more essentially Confucian.
} 


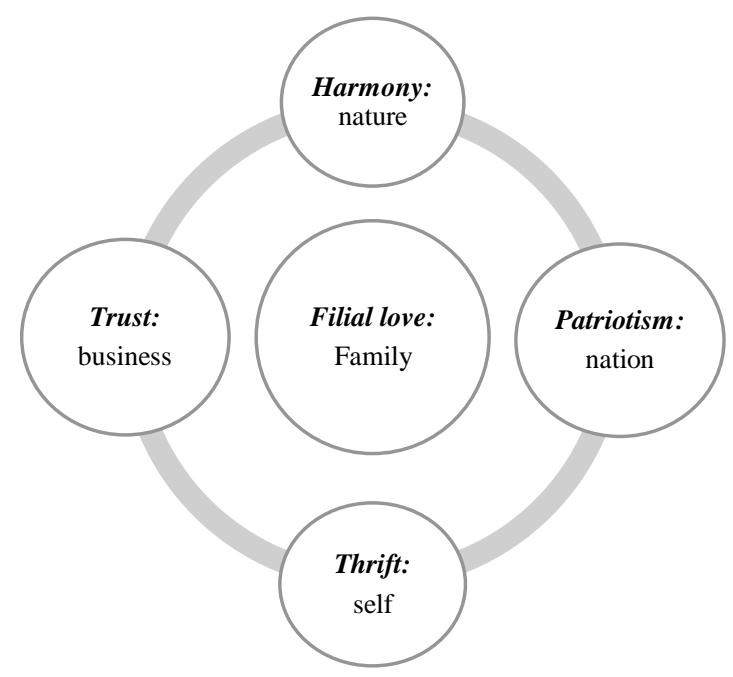

Figure 1. A Chinese Ethical Consumption Framework: Virtues and Relationships

Source: Compiled by the authors

If we examine closely these virtues, organised by their relationships, we are reminded of the "five principal relationships", known as the "hierarchy" in Chinese society, which can be traced back to ancient times (Slote and De Vos, 1998: 121). These relationships are ruler and minister, father and son, elder brother and younger brother, husband and wife, friend, and friend. These principal relationships designate everyone's key relationships within Chinese society. In the book The Great Learning, this progression is clearly recorded: "Their hearts being rectified, their persons were cultivated; their persons being cultivated, their family were regulated; their family being regulated; their States were rightly governed; their States being rightly regulated, the entire world was at peace." This teaching demonstrates the importance of Confucian order that comes from self-cultivation to family-regulation, to state-governance, and finally to world-peace. We wish to reiterate that those five relationships were not superimposed on our data. Our five themes were arrived at inductively through thematic analysis. That those happened to coincide well with the established five relationships in Confucian thought, and with Confucian metaphysics in general, confirmed the active role and value of Confucian thinking in contemporary Chinese culture.

Some Comparisons with Existing Literatures. It would be presumptuous of us to claim that a small-scale qualitative study, such as the one reported on in this paper, has significant theoretical implications in and by itself. However, as the framework suggested above has a firm grounding in previous literature on Confucianism and goes beyond those in some respects, we believe that it constitutes an advance on previous writings to understand Chinese views on ethical consumption. For example, although one of the themes analyzed by the editors of a forthcoming Special Issue on virtue ethics East and West (Alzola, Hennig, and Romar, 2020) comprises "social relationships and role ethics", it does not pinpoint the specific relationships that we identified in Chinese consumers' understanding of ethical consumption. As a theory of selfhood is a fundamental aspect of both Aristotle's and Confucius's virtue ethics, with the latter going beyond the former in positing the additional relationship of the self with nature, we were heartened to see this general self-theory reflected in, and confirmed by, respondents' understanding of the meta-virtue of ethical consumption.

Chen and Moosmayer (2020) come closer to our orientation in highlighting the role of self-concept in Chinese people's understanding of ethical consumption. They looked at the role of an interdependent self-concept in moderating the relationship between guilt and ethical consumption. While Chen and Moosmayer's focus is much more specific than ours, and their approach is moral psychological than moral philosophical, their meticulously designed study foregrounds the need to test empirically the different self-relationships that we identified, as predictors or moderators of ethical consumption. Thompson (2010) explores how Confucian values act as a restraint on the behaviours of a consumerist hedonic lifestyle. Thompson's approach is different from ours in assuming that ethical consumption is about consuming less. Our approach was more focused on getting to grips with what Chinese consumers take ethical consumption to mean, whether such an understanding acts as a barrier to or facilitator of further consumption. Yau and Davies (2015), like us, conducted interviews with Chinese consumers and identified some similar themes. However, their focus was on "sustainable" rather than "ethical" consumption, and they approached ethical consumption from a marketing perspective rather than through an interest in underlying ethical virtues and the conception of ethical consumption couched in virtue language. The suggestions they make are more utilitarian, in a business sense, 
than being built on what they call the "modern renegotiations of traditional Confucian values". Notably, Yau and Davies found "keeping face" to be a formidable motivator of sustainable behaviour but it did not figure in our analysis.

We remain indebted to Garcia-Ruiz and Rodriguez-Lluesma (2014) for their initial analysis of ethical consumption in terms of virtue ethical tenets, and in many ways their article served as the spur to our exploration. They describe a nuanced modern (MacIntyrean) virtue-theory framework that comprehends ethical consumption as a domain-relevant practice, exercising different virtues in pursuit of the life projects of consumers across consumption contexts. Garcia-Ruiz and Rodriguez-Lluesma's characterisations of those projects include detailed descriptions of sustaining family life (Garcia-Ruiz, P., and Rodriguez-Lluesma, C., 2014: 521-522), environmental protection / sustainability (Garcia-Ruiz, P., and Rodriguez-Lluesma, C., 2014: 522-523), and maintaining a community's moral tradition, which often bolsters the prior two (Garcia-Ruiz, P., and Rodriguez-Lluesma, C., 2014: 523-524). They also identify virtues that are exercised in the domain-relative practice of ethical consumption, including moderation, practical wisdom, and constancy (Garcia-Ruiz, P., and Rodriguez-Lluesma, C., 2014: 519-521). Moreover, these authors identified some of the same virtues or lifeprojects in their paper as we did from our data. In particular, our themes of "Family is the centrality", "Necessity, modesty, and thrift" and 'Harmony is the ideal state of being' are in many ways consistent with the findings of Garcia-Ruiz and Rodriguez-Lluesma on family life, moderation / practical wisdom / constancy, and environmental protection, respectively. However, they do not identify either trustworthiness or patriotism, and obviously their analysis is set in a Western virtue ethical context, rather than a Confucian one, which means that even a theme such as environmental projection is grounded in very different metaphysical assumptions from the Confucian ones that seemed to animate the views of our participants about harmony with nature.

Beyond the Ethical Consumption Framework. Acknowledging the complexity of ethical consumption in a Chinese context, cultivating the relevant sub-virtues cannot be simply boiled down to one relationship and one virtue at a time, although the above framework offers a helpful lens to understand the overall characterological associations of the concept among Chinese consumers. Just like the complex nature of the notion of ethical consumption itself, its virtues may often only be conceptualised and exercised as a bundle. We could call "ethical consumption" a meta-virtue or an "umbrella virtue", therefore. This bundle does not operate in a fixed order, but rather the elements interact with the external environment, and thus the virtues used are influenced by specific situations to provide the basis for ethical consumption within the given context. Furthermore, internal dilemmas can be generated within the bundle. For example, the New Zealand Kiwi fruit story, on the one hand, shows the loving generosity of the father towards his child, and on the other hand, it may seem to contradict the virtue of frugality. This can then be interpreted as a virtue conflict between generosity and thrift. As stated, both in Aristotelianism and Confucianism, the golden mean of virtue always requires the right amount, at the right time and right place. As well as conflicts within a theme, or a sub-virtue, conflicts can also arise between sub-virtues ( $q u a$ the themes identified above). For example, patriotism motivates the capacity of local brands to forge bonds with Chinese consumers and win their hearts. Huaiwei is regarded as "the pride of the nation" by some Chinese media, as a strong Chinese domestic brand that can compete with Apple and Samsung. Consumers who support Huaiwei often think that they are supporting their nation, like the participant who purchased a new Huaiwei mobile to replace his iPhone: reflecting, in particular, a response to the trade wards with the USA in recent years. Meanwhile, recall the mother who was keen on purchasing imported baby formula and the father who purchased the New Zealand kiwi. There, family love trumped patriotism. It is crucial, therefore, to understand the dynamics of the framework in a practical consumption context.

Because of its acute sensitivity to contextual factors, Confucianism is even better equipped than Aristotelianism to identify and resolve contextual conflicts. Both Aristotle and Confucius saw human beings as "political animals". However, the holism regarding the place of the individual within a given socio-political context has gradually been lost in Western virtue ethics (although partly retrieved by MacIntyre, 1981). Confucianism resonates better in this regard nowadays because of the unique role the State and the community still play in Chinese society (cf. Ackerman, $\mathrm{Hu}$, and Wei, 2009). One way to put this is to say that all Confucian virtues are, by their very nature, relational and communal. Ethical consumption can, thus, be specified as a relational and communal meta-virtue that consumers, business and other stakeholders exercise in the consumption process. Although it is difficult to transpose deep-grained cultural ideas to other cultures, we cannot resist the temptation to suggest that this understanding of the relational nature of the virtues constituting ethical consumption would enrich the concept internationally. Ethical consumption should not be about purchasing A or B but rather about exercising virtues in properly contextualised bundles and within relationship networks. Hence, to prompt the right virtues within the right relationships is vital. From a business 
perspective, Chinese firms like Huaiwei have successfully drawn on this cultural understanding by associating their products with patriotism and thus adding to their competitiveness when competing with foreign companies. For foreign firms trading with China, the key is to tap into this local understanding also. Endorsing Chinese patriotism may be too tall an order for most of them, but emphasising other virtues in the bundle, for example, family love and filial duties, could both be seen as ethical, locally embraced and attractive. Above all, businesses who can truly exercise the virtue of trustworthiness restore the essence of ethical consumption by establishing a stable relationship with their consumers.

Our empirical data indicate that it would be futile to try to impose a Western conception of ethical consumption on Chinese consumers directly. Whether the converse is also true is more moot. Although the five virtuerelevant themes identified above are obviously Chinese themes, most of them have counterparts in Western virtue ethics, so it is perhaps not too far-fetched to hypothesise that Western understandings of ethical consumption could be enriched by more familiarity with Chinese understandings. For example, given the rising interest in character education (which is basically the educational incarnation of virtue ethics) in Western schools, this interest would seem to present ideal opportunities to introduce virtue-based conceptions of ethical consumption to young learners. As the Confucian take on them is in many ways richer than the Aristotelian one, we do not think that the Chinese provenance will necessarily present a barrier to their potential inclusion in Western curricula. It would be in the best interest of marketers and policy makers to strive to create a consumption environment that communicates these virtues, explicitly and inexplicitly: for example, by having the virtues be made more perceivable in their advertisement and slogans. This then would also require allround attention from all stakeholders. Firms who can stimulate their consumers to exercise more virtues should be recognised as being "morally optimal" or "ethical excellence" firms. Although the vocabulary of the Chinese consumers we spoke to was, in some respect, less developed than that of Western consumers, what characterised it was the notion that ethical consumption is not a high-minded ideal but part of 'common sense'. This notion holds promise of making ethical consumption easier to inculcate in Chinese society than in the West where it is seen more as an ideal to aim at, or even a supererogatory value, than a requirement of common sense. Western virtue ethics has a hard time dealing with virtue conflicts, witness the complex literatures on the meta-intellectual virtue of phronesis or practical wisdom, of which only the fully developed phronimos is supposed to be in full command (Darnell et al., 2019). However, the corresponding Confucian virtue of zhongyong (中庸) is more about the ordinary integration by an ordinary person of the daily commands involved in living a decent life.

\section{Conclusion}

This study aimed to reconceptualise the ideal of ethical consumption in virtue ethical language from a Confucian perspective and provide an authentic perspective of Chinese consumers' understandings of ethical consumption. Through their "life worlds", that is their daily consumption experiences and life stories, they illuminate these "taken-for-granted" experiences and uncover new and/or forgotten meanings (Wilson and Hutchinson, 1991). This is also reflected in the chosen phenomenological stance. Rather than seeking one universal truth, we focused on exploring consumers' experiences inside the relevant culture and social context (Webster and Mertova, 2007). The ideal that consumers' voices should be heard is a cherished one (Alvessson and Skoldberg, 2000). However, this study does not claim to represent the complete truth of Chinese consumers' views on ethical consumption, considering the geographic constraints and the small number of participants. Future research could gather a greater variety by exploring consumers' understandings from different geographic and sub-cultural areas, for example, to explore consumers' understandings of ethical consumption from an advanced urban perspective as well as a developing rural perspective, to compare their similarities and differences. This could also be explored via specific age groups, such as how youth and adults perceive ethical consumption differently, as well as via a gender perspective, between males and females. It would also be interesting to include both Chinese and Western consumers, to ask them about the same issues and learn their opinions to obtain an even more vivid and dynamic cross-cultural understanding about ethical consumption. In addition, future research could also adopt a quantitative approach that explores the roles and levels of specific virtues, i.e., if certain virtues are valued more than the others in the context of ethical consumption. Chinese consumers' understanding of ethical consumption is not a rigid set of rules or purely outcome-orientated; it reflects the usefulness of a virtue ethics approach to ethical consumption, grounded in their daily practices and reflecting what motivates them, especially virtues such as filial piety/love, thrift, trust, harmony and patriotism. To couch our findings in virtue ethical language, "ethical consumption" for Chinese consumers seems to function as a virtue-based concept, encapsulating what we could call a meta-virtue. This meta-virtue thus functions very much like magnanimity (megalopsychia) in Aristotle's system (Kristjánsson, 2020), 
except its object is not views of self-worth but of the relationship of the self towards several different variables, all having to do with consumption practices.

Confucian teachings on the moral exemplar of $j u n-z i$ have implications for Chinese ethical consumers, for just like jun-zi pursues a virtuous life, consumers can cultivate virtues in their daily consumption practices. This study has demonstrated the resilience and persistence of Confucianism in Chinese society. A study of the concept of ethical consumption inevitably brings the central discourse to virtues. Thus, a re-evaluation of consumer virtues and their implications for consumers' consumption behaviours must be introduced to the research agenda of ethical consumption. The lessons of this study do not only carry implications for the Chinese context. A lot of what counts as analysis of ethical consumption in the West is based on the conceptions of "the wise" only. In the first part of the paper, we described the Western theoretical models of ethical consumption, which are largely drawn from deontology and consequentialism, and noted that there should be room for a virtue ethical approach. In the empirical part, we then observed that Chinese consumers adopt a different, namely Confucian, approach to ethical consumption. We realise that there is a possible incongruity here in the sense that the claims about the Chinese consumers are "psychological" whereas the claims about the West are based on "theory". The "psychology" of Western consumers might, for all we know, be like that of our sample. We acknowledge, therefore, that a possible similar study of the views of "the many" in the West might possibly reveal less divergence between lay views of ethical consumption in the West and the East than the current academic literatures seem to indicate. ${ }^{9}$

Author Contributions. Conceptualization, Yan Huo \& Kristján Kristjánsson; literature review, Yan Huo \& Kristján Kristjánsson; methodology, Yan Huo; formal analysis, Yan Huo; writing, Yan Huo \& Kristján Kristjánsson, original draft, Yan Huo; writing, review and editing, Yan Huo \& Kristján Kristjánsson; project and administration, Yan Huo; supervision, Philippa Ward, Lily Wang.

Funding. There is no funding for this research.

\section{References}

1. Abdur, R.M., and Hwee, T.P. (2002). Ethics and purchasing dilemma: A Singaporean view. Journal of Business Ethics, 35(4), 307-326. DOI:10.1023/A:1013853021571.

2. Ackerman, D., Hu, J., and Wei, L. (2009). Confucius, cars, and big government: Impact of government involvement in business on consumer perceptions under Confucianism. Journal of Business Ethics, 88(3), 473-482. DOI:10.2307/27749720.

3. Allon, F. (2011). Ethical consumption begins at home: Green renovations, eco-homes and sustainable home improvement. In T. Lewis and E. Potter (Eds.), Ethical consumption: A critical introduction (pp.202-215). New York: Routledge. https://doi.org/10.4324/9780203867785.

4. Alzola, M. (2015). Virtuous persons and virtuous actions in business ethics and organizational research. Business Ethics Quarterly, 25(3), 287-318. DOI:10.1017/beq.2015.24.

5. Alzola, M., Hennig, A., and Romar, E. (2020). Thematic symposium editorial: Virtue ethics between East and West. Journal of Business Ethics, in press. Retrieved from https://link.springer.com/article/10.1007\%2Fs10551-019-04317-2.

6. Barnett, C. Cafaro, P., and Newholm, T. (2005). Philosophy and ethical consumption. In R. Harrison, T. Newholm, D. Shaw (Eds.): The ethical consumer (pp.11-24). London: Sage. Available at: https://www.escholar.manchester.ac.uk/uk-ac-man-scw:4b2293.

7. Braun, V., and Clarke, V. (2006). Using thematic analysis in psychology. Qualitative Research in Psychology, 3(2), 77-101. DOI:10.1191/1478088706qp063oa.

8. Bray J., Johns N., and Kilburn D. (2010). An exploratory study into the factors impeding ethical consumption. Journal of Business Ethics, 98(4), 597-608. DOI:10.1007/s10551-010-0640-9.

9. Burke, S.J., Milberg, S.J., and Smith, N.C. (1993). The role of ethical concerns in consumer purchase behavior: Understanding alternative processes. Advances in Consumer Research, 20(1), 119-122. DOI:10.1016/0361-3682(93)90026-3.

\footnotetext{
${ }^{9}$ One possible way to search for further convergence between Western and Confucian views of ethical consumption would be to re-analyse our data not in terms of moral virtues but in terms of deeper universal "moral foundations". If our identified themes are seen to refer to foundational values rather than virtues, many of the above findings could be assimilated to Haidt's (2012) moral foundations, and possibly serve as confirmations of the crosscultural validity of those foundations. For instance, patriotism could be assimilated to Haidt's intuitive moral foundation of loyalty, respondents' sympathy for the infants poisoned by adulterated baby formula, reported on in the section on trustworthiness, could be assimilated to Haidt's moral foundation of care, and respondents' distaste for fast-growing chicken could be assimilated to Haidt's moral foundation of purity. We leave the elaboration of those considerations for another day, however.
} 
10.Carrigan, M., and Attalla, A. (2001). The myth of the ethical consumer: Do ethics matter in purchase behaviour? Journal of Consumer Marketing, 18(7), 560-577. DOI:10.1108/07363760110410263.

11.Chen, Y., and Moosmayer, D.C. (2020). When guilt is not enough: Interdependent self-construal as moderator of the relationship between guilt and ethical consumption in a Confucian context. Journal of Business Ethics, 161(3), 551-572. DOI:10.1007/s10551-018-3831-4.

12.Cherrier, H. (2005). Using existential-phenomenological interviewing to explore meanings of consumption. In R. Harrison, T. Newholm, and D. Shaw (Eds.), The ethical consumer (pp. 125-135). London: Sage. Available at: https://www.escholar.manchester.ac.uk/uk-ac-man-scw:4b2293.

13.Chesterley, N. (2016). Virtue and vice with endogenous preferences. Economic Theory Bulletin, 4(2), 199-211. DOI:10.1007/s40505-015-0078-4.

14.Chu, I., and Moore, G. (2019). From harmony to conflict: MacIntyrean virtue ethics in a Confucian tradition. Journal of Business Ethics, in press. Available at: https://link.springer.com/article/10.1007\%2Fs10551-019-04305-6\#citeas.

15.Clandinin, D.J., and Huber, J. (2007). Narrative inquiry. In B. McGaw, E. Baker, and P.P. Peterson (Eds.), International encyclopedia of education. New York: Elsevier. Available at: http://www.mofet.macam.ac.il/prof/sadnaot/selfstudy/Documents/NarrativeInquiry.pdf.

16.Clavin, B., and Lewis A. (2005). Focus groups on consumers' ethical beliefs. In R. Harrison, T. Newholm, and D. Shaw (Eds.), The ethical consumer (pp. 173-187) London: Sage. Available at: https://www.escholar.manchester.ac.uk/uk-ac-man-scw:4b2293.

17.Clouder, S. and Harrison, R. (2005). The effectiveness of ethical consumer behaviour. In R. Harrison, T. Newholm, and D. Shaw (Eds.), The ethical consumer (pp. 89-102). London: Sage. Available at: https://www.escholar.manchester.ac.uk/uk-ac-man-scw:4b2293.

18.Confucius (2014). The Analects. New York: Penguin Books. 256 p. Available at: http://infinity.wecabrio.com/143106856-the-analects-penguin-classics.pdf.

19.Co-operative Bank Report (2011). Ethical Consumerism Report. Available at: https://www.cooperativebank.co.uk/.

20.Crane, A., and Matten, D. (2004). Business ethics. Oxford: Oxford University Press. ISBN: 0-19-925515-6. $506 \mathrm{p}$.

21.Darnell, C., Gulliford, L., Kristjánsson, K., and Panos, P. (2019). Phronesis and the knowledge-action gap in moral psychology and moral education: A new synthesis? Human Development, 62(3), 101-129. DOI:10.1159/000496136.

22.Devinney, T.M., Auger, P., and Eckhardt, G.M. (2010). The myth of the ethical consumer. Cambridge: Cambridge University Press. DOI:10.5840/beq201323444.

23.Fisher, B., Turner, R.K., and Morling, P. (2009). Defining and classifying ecosystem services for decision making. Ecological Economics, 68(3), 643-653. DOI:10.1016/j.ecolecon.2008.09.014.

24.Gallie, W. B. (1956). Essentially contestable concepts. Proceedings of the Aristotelian Society, 56, 167-198. DOI:10.5840/inquiryctnews19941415.

25.Gao, X.H. (2013). Revisiting the golden arches in China: The Chinese discourse on McDonald's between 1978-2012. Journal of Marketing, 33(4), 288-305. DOI:10.1177/0276146713493805.

26.Garcia-Ruiz, P., and Rodriguez-Lluesma, C. (2014). Consumption practices: A virtue ethics approach. Business Ethics Quarterly, 24(4), 509-531. DOI:10.5840/beq20147313.

27.Haidt, J. (2012). The righteous mind: Why good people are divided by politics and religion. New York: Pantheon Books. DOI:10.1017/S0953820813000253.

28.Harrison, R., Newholm, T., and Shaw, D. (Eds.). (2005). The ethical consumer. London: Sage. Available at: www.manchester.ac.uk/escholar/uk-ac-man-scw:4b2293.

29.Huang, J.J. (2005). Discussions on Confucianism's "human" and "nature" relationships: Implications for $21^{\text {st }}$ century. Modern Philosophy, 1, 59-67. DOI:10.3969/j.issn.1000-7660.2005.01.008.

30.Humphry, K. (2011). The simple and the good: Ethical consumption as anti-consumerism. In T. Lewis, and E. Potter (Eds.), Ethical consumption: A critical introduction (pp. 40-53). New York: Routledge. https://doi.org/10.4324/9780203867785.

31.Huo, Y., and Kristjánsson, K. (2018). Why is there lack of growth in character virtues? An insight into business students across British business school. In D. Carr (Ed.), Cultivating moral character and virtue in professional practice (pp. 207-221). London: Routledge. Available at: https://mysuccesskeys.com/cultivating-moral-character-and-virtue-in-professional-practice/.

32.Husserl, E. (1970). The idea of phenomenology. The Hague: Nijhoff. ISBN:978-90-247-0114-8. Available at: https://www.springer.com/gp/book/9780792356912. 
33.Joergens, C. (2006). Ethical fashion: Myth or future trend? Journal of Fashion Marketing and Management, 10(3), 360-371. DOI:10.1108/13612020610679321.

34.Jordan, K., and Kristjánsson, K. (2017). Sustainability, virtue ethics, and the virtue of harmony with nature. Environmental Education Research, 23(9), 1205-1229. DOI:10.1080/13504622.2016.1157681.

35.Kent, T. (2005). Ethical perspectives on the erotic in retailing. Qualitative Market Research, 8(4), 430-439. doi:10.1108/13522750510619788.

36.Kirkman, M. (2002). What's the plot? Applying narrative theory to research in psychology. Australian Psychologist, 37(1), 30-38. DOI:10.1108/13522750510619788.

37.Kong, D.X. (2009). A discussion on Confucius consumption views. Journal of Xuchang University, 28(1), 94-96. DOI:10.3969/j.issn.1671-9824.2009.01.026.

38.Kozinets, R.V., and Handelamn, J.M. (1998). Ensouling consumption: A netnographic exploration of boycott behavior. Advances in Consumer Research, 25, 475-480. Available at: https://www.researchgate.net/publication/235356525_Ensouling_Consumption_A_Netnographic_Explora tion_of_the_Meaning_of_Boycotting_Behavior.

39.Kristjánsson, K. (1996). Social freedom: The responsibility view. Cambridge: Cambridge University Press. DOI: $10.1017 /$ S0012217300010039.

40.Kristjánsson, K. (2020). Flourishing as the aim of education: A neo-Aristotelian view. London: Routledge. ISBN:9780429464898. 228 p. Available at: https://www.routledge.com/Flourishing-as-the-Aim-ofEducation-A-Neo-Aristotelian-View/Kristjansson/p/book/9780367727970.

41.Langdridge, D. (2007). Phenomenological psychology: Theory, research and methods. London: Pearson. DOI: $10.1108 / 17465640710778548$.

42.Laverty, S.M. (2003). Hermeneutic phenomenology and phenomenology: A comparison of historical and methodological considerations. International Journal of Qualitative Methods, 2(3), 21-35. DOI:10.1177/160940690300200303.

43.Lee, M.H. (2015). Lone no more: The sociable ethical consumer. Thesis submitted for the degree of Doctor of Philosophy at the University of Leicester. Available at: https://ethos.bl.uk/OrderDetails.do?uin=uk.bl.ethos.643674.

44.Littler, J. (2010). What is wrong with ethical consumption? In T. Lewis, and E. Potter (Eds.), Ethical consumption: A critical introduction (pp. 27-39). New York: Routledge. doi/10.9774/GLEAF.9780203867785_3.

45.MacIntyre, A. (1981). After virtue. Notre Dame: University of Notre Dame Press. DOI:10.1017/S0360966900022416.

46.MacIntyre, A. (1999). Dependent rational animals. New York: Bloomsbury Academic. DOI:10.5216/phi.v6i1/2.3133.

47.McGrath, R.E., and Walker, D.I. (2016). Factor structure of character strengths in youth: Consistency across ages and measures. Journal of Moral Education, 45(4), 400-418. DOI:10.1080/03057240.2016.1213709.

48.Markus, H.R., and Kitayama, S. (1991). Culture and self: Implications for cognition, emotion, and motivation. Psychological Review, 98(2), 224-253. Available at: https://web.stanford.edu/ hazelm/publications/1991\%20Markus\%20Kitayama\%20Culture\%20and\%20th e\%20self.pdf.

49.O'Rourke, D. (2006). Looking behind the label: ethical consumption issues today. In T. Daly, C. Regan, and C. Regan (Eds.) Development in an unequal world (pp. 291-302). New Internationalist: Pixelpress. doi/10.18546/IJDEGL.09.2.05.

50.Ouyang, Z.R. (2015). On the relationship between man and nature in The Great Learning and The Doctrine of the Mean. China Culture Research, 1, 12-20. Available at: http://www.cnki.com.cn/Article/CJFDTotalZWHY201501002.htm.

51.Peterson, C., and Seligman, M.E.P. (2004). Character strengths and virtues: A handbook and classification. New York: Oxford University Press. ISBN:0-19-516701-5. 800 p. Available at: https://www.apa.org/pubs/books/4317046.

52.Percy, I. (2006). Living reflexive qualitative research: resonance and authenticity. In J. Higgs, A. Titchen, H. Armstrong, and D. Horsfall (Eds.). Being critical and creative in qualitative research (pp. 97-107). Sydney: Hampden Press. Available at: https://www.researchgate.net/publication/288542815 Living Reflexive Qualitative Research Resonanc e_and_Authenticity.

53.Regan, T. (2004). The case for animal rights. Berkeley: University of California Press. DOI:10.1007/97894-009-3331-6_15. 
54.Reynolds, J.L. (2019). An economic analysis of international environmental rights. International Environmental Agreements: Politics, Law and Economics, 19(6), 557-575. DOI:10.1007/s10784-01909454-7.

55.Real Think Tank (2007). Retailers are not influenced by ethical consumers. Retail Think Tank White Paper. Available at: http://www.retailthinktank.co.uk/whitepaper/retailers-are-not-influenced-by-ethicalconsumers-its-simply-that-a-socially-responsible-retailer-is-more-profitable/.

56.Shaw, D., and Clarke, I. (1999). Belief formation in ethical consumer groups: An exploratory study. Marketing Intelligence and Planning, 17(2), 109-119. DOI:10.1108/02634509910260968.

57.Shaw, D., and Shiu, E. (2003). Ethics in consumer choice: a multivariate modelling approach. European Journal of Marketing, 37(10), 1085-1099. DOI:10.1108/03090560310487202.

58.Shenton, A.K. (2004). Strategies for ensuring trustworthiness in qualitative research projects. Education for Information, 22(1), 63-75. DOI:10.3233/EFI-2004-22201.

59.Sigurðsson, G. (2014). Frugalists, anti-consumers, and prosumers: Chinese philosophical perspectives on consumerism. In A. Hulme (Ed.), The changing landscape of China's consumerism (pp. 125-149). London: Chandos. DOI: $10.1533 / 9781780634425.125$.

60.Silverman, D. (2013). Doing qualitative research. London: Sage. doi:10.1364/AO.45.000335.

61.Sim, M. (2007). Remastering morals with Aristotle and Confucius. Cambridge: Cambridge University Press. 240 p. Available at: https://www.twirpx.com/file/2550676/.

62.Singer, P. (1997). How are we to live? Ethics in the age of self-interest. Oxford: Oxford University Press. Available at: phr199710616.

63.Singer, P. (2002). One world: The ethics of globalization. New Haven: Yale University Press. http://dx.doi.org/10.1111/j.1523-1739.2004.1812 2.x.

64.Sison, A.J.G., Beabout, G.R., and Ferraro, I. (Eds.) (2017). Handbook of virtue ethics in business and management. Dordrecht: Springer. Available at: https://www.springer.com/gp/book/9789400765092.

65.Slote, W.H., and De Vos, G.A. (1998). Confucianism and the family. New York: State University of New York Press. Available at: https://ci.nii.ac.jp/ncid/BA37996566.

66.Smith, N.C. (1990). Morality and the market: Consumer pressure for corporate accountability. London: Routledge. DOI:10.2307/2393461.

67.Solomon, R.C. (2004). Aristotle, ethics and business organizations. Organization Studies, 25(6), 1021-1043. DOI: $10.1177 / 0170840604042409$

68.Szmigin, I., and Carrigan, C. (2006). Exploring the dimensions of ethical consumption. European Advances in Consumer Research, 7, 608-613. Available at: https://www.acrwebsite.org/volumes/eacr/vol7/europeanvolume7_25.pdf.

69.Thompson, M. (2010) Signals of virtue in Chinese consumerism and business. Journal of International Business Ethics, 3(2), 71-79. Available at: https://www.docin.com/p-1594882936.html.

70.Tu, W.M. (2014). The global implications of the doctrine of ren: The humanistic spirit and ecological awareness of Confucianism. Confucian Academy, 001(001), 12-29, 117-135. Available at: http://www.cnki.com.cn/Article/CJFDTotal-KXTK201401010.htm.

71.Wajda, T.A., Hu, M.Y., and Cui, A.P. (2007). Self-evaluation shopping/consumption motives: Identifying differences in the U.S. and China. Journal of Global Marketing, 21(1), 49-62. DOI:10.1300/J042v21 n01-05.

72.Webster, L., and Mertova, P. (2007). Using narrative inquiry as a research method. London: Routledge. https://doi.org/10.4324/9780203946268.

73.Wilson, H., and Hutchinson, S. (1991). Triangulation of qualitative methods: Heideggerian hermeneutics and grounded theory. Qualitative Health Research, 1(2), 263-276. DOI:10.1177/104973239100100206.

74. Yau, A., and Davies, I. (2015). The modern renegotiations of Confucian ethics and implications on ethical consumption in China. In L. Robinson (Ed.), Marketing dynamism and sustainability: Things change, things stay the same. Developments in Marketing Science: Proceedings of the Academy of Marketing Science (pp. 212-221). Dordrecht: Springer. Available at: https://link.springer.com/chapter/10.1007/978-3-31910912-1_70.

75.Yu, J.Y. (2007). The ethics of Confucius and Aristotle: Mirrors of virtue. New York: Routledge. 292 p. DOI:10.1353/pew.0.0105 